\title{
A Study to Compare and Evaluate the Efficacy of Granisetron and Granisetron Dexamethasone Combination as Anti-Emetic
}

\author{
Asha Rani BN ${ }^{1}$, Swati Bhatt ${ }^{2}$ \\ ${ }^{1}$ Assistant professor, Department of Anesthesia, Sanjay Gandhi Institute of Trauma and Orthopedics, Bangalore, Karnataka, ${ }^{2}$ Professor, Department of Anesthesia, \\ Baroda Medical College, Vadodara.
}

\section{Abstract}

\begin{abstract}
Background: Dexamethasone, a glucocorticoid is shown to produce stronger antiemetic effect, probable mechanism is prostaglandin antagonism, serotonin inhibition, releasing endorphins and 5HT3 antagonism with biological half life 36 to 72 hrs, confers longer duration of prophylaxis.Since etiology of PONV is multifactorial, combination of different classes of antiemetic can increases clinical efficacy compared to single drug alone. Subjects and Methods: A detail preoperative assessment was performed on preoperative visit on the day before surgery. Where detail history, thorough general examination, airway assessment and systemic examination was performed. All routine investigations were done like haemogram, routine urine examination, random blood sugar, blood urea, serum creatinine and serum liver function test.X-ray chest and ECG were done when indicated. Results: In Group-GD, only 13.33\% had PONV which was statistically significantly low as compared to Group-G which was $36.66 \%(\mathrm{P}<0.05)$. Complete response in Group-GD was $86.67 \%$ which was statistically significantly high as compared to Group-G which was only $63.34 \%(\mathrm{P}<0.05)$. Conclusion: Requirement of Rescue anti-emetic was less in Granisetron-Dexamethasone combination group than Granisetron group.
\end{abstract}

Keywords: Granisetron, Granisetron Dexamethasone combination, Anti-emetic.

Corresponding Author: Dr. Swati Bhatt, Professor, Department of Anesthesia, Baroda Medical College, Vadodara.

Received: August 2019

Accepted: August 2019

\section{Introduction}

Post operative nausea and vomiting is still one of the most common and distressing symptom Following surgery and anaesthesia despite significant advances in conduction of general anaesthesia and surgery. kapur has described this as "THE BIG LITTLE PROBLEM"

The overall incidence of PONV is $25-30 \%$ and second most common compliant reported, and incidence of severe and intractable PONV is $0.19 \%$. Several large prospective cohort studies now suggest that the varying incidences of PONV observed after different types of surgeries are largely a reflection of important patient specific and anaesthesia related risk factors rather than surgery itself. ${ }^{[1]}$

Regarding anaesthesia related risk factor the inhalation agents are invariably associated with PONV, nitrous oxide, cyclopropane, ether are associated with high incidence while currently used agents like isoflurane, enflurane and sevoflurane cause less but still significant PONV. IV anaesthetics are also associated with different degrees of emesis, though newer agents like propofol is less emetoginic and opoids used is also emetoginic.

Patient related factor also being important, PONV is more prevalent in females than males, obesity, pregnancy, children more susceptible, previous h/oPONV, motion sickness are known risk factors

Although PONV is almost always self limiting and non fatal it can cause significant morbidity and longer stays in recovery room.It can have psychological impact which will cause aversion to further surgery and apprehension of repeated vomiting. ${ }^{[2]}$

Thus PONV leads to physical, metabolic, psychological and economical impact. Etiology of PONV is multifactorial, at least 7 neurotransmitter types are documented namely serotonin, dopamine, muscarine, ach, neurokinin1, histamine and opoids. Stimulation of vestibulocochlear, glossopharyngeal, vagus nerve is also being involved.

Granisetron a newer highly specific 5HT3 receptor antagonist, having both central and peripheral action, having longer half life twice that of ondensetron and fewer side effect as compared to metoclopramide, is effective in PONV. ${ }^{[3]}$

Recently, Dexamethasone, a glucocorticoid is shown to produce stronge antiemetic effect, probable mechanism is prostaglandin antagonism, serotonin inhibition, releasing endorphins and 5HT3 antagonism with biological half life 36 to $72 \mathrm{hrs}$, confers longer duration of prophylaxis. Since etiology of PONV is multifactorial, combination of different classes of antiemetic can increases clinical efficacy compared to single drug alone. Therefore, Combination of 
Granisetron and Dexamethasone is effective in preventing PONV by their synergistic effect 5HT3 antagonism, and multiple receptor site action.

Laparoscopic surgery also called minimal invasive surgery, banded surgery, key hole surgery, in which operation in abdomen is performed through small incision. laparoscopic surgeries have been rapidly increased because of tremendous benefits to patients with smaller incision than convention technique, scarless surgery ( minimal tissue trauma), decrease post operative pain, decrease post operative ileus, decrease post operative pulmonary impairment, shorter hospital stay and earlier ambulation ,despite all these high incidence of PONV remains a major cause of morbidity. ${ }^{[4]}$

Laparoscopic cholecystectomy is now a days the preferred procedure for cholelithiasis although it can decrease surgical morbidity in comparison to open cholecystectomy, the incidence of PONV is appreciably high, relatively high incidence $53-72 \%$ compared to other laparoscopic surgeries. It is more common in female and obese patients. This high incidence justifies the use of prophylactic antiemetic for prevention of PONV following laparoscopic cholecystectomy. ${ }^{[5]}$

Therefore, we decided to carry out comparative study of combination of Granisetron with Dexamethasone and Granisetron alone for prevention of PONV in laparoscopic cholecystectomy.

\section{Subjects and Methods}

The randomized prospective clinical study of 60 patients undergoing Laparoscopic cholecystectomy were carried out at Medical College. Patients were randomly divided into two group;

\section{GROUP - G}

Inj. Granisetrone $(40 \mu \mathrm{g} / \mathrm{kg})$ in $5 \mathrm{ml}$ NS Intravenously.

\section{GROUP-GD}

Inj. Granisetrone $(40 \mu \mathrm{g} / \mathrm{kg})+$ Inj. Dexamethasone $(150 \mu \mathrm{g} / \mathrm{kg})$ in $5 \mathrm{ml} \mathrm{NS}$ intravenously.

\section{Patient Selection and Preoperative Assessment}

A detail preoperative assessment was performed on preoperative visit on the day before surgery. Where detail history, thorough general examination, airway assessment and systemic examination was performed. All routine investigations were done like haemogram, routine urine examination, random blood sugar, blood urea, serum creatinine and serum liver function test.

$\mathrm{X}$-ray chest and ECG were done when indicated.

\section{Anaesthesia Technique}

On the day of surgery, nil by mouth status of patient was confirmed and written and informed consent obtained.Intravenous line was secured with crystalloid infusion was started.

\section{Premedication}

In all the patients of either group premedication was given in the form of

Injection Glycopyrrolate $[5 \mu \mathrm{g} / \mathrm{kg}]$ intramuscularly 1 hour

\section{before induction}

Moniters were attached and all baseline parameters pulse rate, blood pressure, respiratory rate \& Spo2 \& ECG were recorded and patients were randomaly divided on two groups;

\section{GROUP - G}

Inj. Granisetrone $(40 \mu \mathrm{g} / \mathrm{kg})$ in $5 \mathrm{ml}$ NS Intravenously.

\section{GROUP - GD}

-Inj. Granisetrone $(40 \mu \mathrm{g} / \mathrm{kg})+$ Inj. Dexamethasone $(150 \mu \mathrm{g} / \mathrm{kg})$ in $5 \mathrm{ml} \mathrm{NS}$ intravenously.

Haemodynamic parameters were observed by same observer after giving drugs.

- Then, Inj. Fentanyl $[1 \mu \mathrm{g} / \mathrm{kg}]$ was given intravenously 5 minute before induction in both the groups.

\section{Induction}

All patients received general anaesthesia. After pre oxygenation $100 \%$ O2 for 3 minutes. Patients were induced with Inj. Sodium Thiopentone $4-7 \mathrm{mg} / \mathrm{kg}$ i.v.till loss of eye lash reflex, Inj. Succinyl choline i.v. $2 \mathrm{mg} / \mathrm{kg}$ followed by tracheal intubation with cuffed portex ET tube of appropriate SIze. Appropriate size ryle's tube was inserted and aspiration was done.

\section{Maintenance}

Anaesthesia was maintained with controlled ventilation oxygen $(50 \%)+\mathrm{N} 2 \mathrm{O}(50 \%)+$ Isoflurane $(0.8-2 \%)$ and intermittent Inj. Vecuronium bromide $(0.02 / \mathrm{KG})$ intravenously.

Intraabdominal pressure was kept between 11$15 \mathrm{mmhg}$.throughout the course of anaesthesia patients were monitored forhaemodynamic parameters pulse, blood pressure, ETCO2, Spo2 and ECG.

\section{Reversal}

After completion of surgery, ryle's tube aspiration was done, than patients were reversed with Inj. Glycopyyrolate $10 \mu \mathrm{g} / \mathrm{kg}$ and Inj. Neostigmine $50 \mu \mathrm{g} / \mathrm{kg}$ i.v.and after fulfilling all the criteria of extubation, patients were extubated.

Vital data were recorded postoperatively and all the patients were shifted to recovery room and oxygen was given through ventimask.

In the post operative period, patients were monitored immediately, than 15mins, 30mins, 45mins, 1 hour, 2 hour, 3 hour, 4hour, 6hour, 8hour, 12hour and 24 hour for haemodynamic parameters,sp02, respiratory rate, any episode of nausea, retching or vomiting, Emesis score, requirements of rescue anti-emetic and side effects.

\section{Emesis Score}

- SCORE 0 ;- No Nausea

- $\quad$ SCORE 1 ;- Nausea only

- $\quad$ SCORE 2 ;- Nausea with Retching

- $\quad$ SCORE 3 ;- Vomiting

Rescue Anti-Emetic was given in the form of Inj. Ondensetron $4 \mathrm{mg}$ Intravenously when Emesis score was $\geq 2$ $\&$ this was considered as end point of study. 


\section{Cambination as Anti-Emetic}

- Nausea: It is defined as a subjective unpleasant sensation associated with awareness and a desire to vomit but not associated with expulsive muscular movement.

- Retching: It is defined as a labored, spasmodic, rhythmic contraction of respiratory muscle including diaphragm, chest wall and abdominal muscle without

Results expulsion of gastric content.

- Vomiting: It is defined as a forceful expulsion of gastric content from the mouth and brought about by powerful sustain contraction of abdominal muscle, descent of diaphragm and opening of cardiac sphincter.

Table 1: Demographic characteristics

\begin{tabular}{|l|l|l|l|}
\hline Variables & Group- G Mean \pm SD & Group- GD Mean $\pm S D$ & Intergroup'P' Value \\
\hline Age(year) & $42.63 \pm 8.48$ & $43.56 \pm 8.05$ & $>0.05$ \\
\hline Weight(kg) & $55.13 \pm 6.47$ & $57.13 \pm 7.41$ & $>0.05$ \\
\hline
\end{tabular}

The patients in Group- $\mathrm{G}$ had average age 42.63 years and average weight of $51.13 \mathrm{~kg}$. Group- GD patients had average age 43.56 and average weight of $57.13 \mathrm{~kg}$. Both groups were comparable with respect to age and weight $(\mathrm{P}>0.05)$.

Table 2: Gender Distribution

\begin{tabular}{|l|l|}
\hline Variables & Group- G \\
\hline Male & $11[36.66 \%]$ \\
\hline Female & $19[63.33 \%]$ \\
\hline
\end{tabular}

[Table-2] shows gender distribution, $36.66 \%$ of patient in Group- $G$ were male and $63.33 \%$ were females. Group- GD

\begin{tabular}{|l|l|}
\hline Group- GD & Intergroup'P' Value \\
\hline $12[40 \%]$ & $>0.05$ \\
\hline $18[60 \%]$ & $>0.05$ \\
\hline
\end{tabular}

had $40 \%$ male and $60 \%$ were female.both groups were comparable $(\mathrm{P}>0.05)$

Table 3: ASA Status
\begin{tabular}{|l|l|l|l|l|}
\hline ASA Grade & Group - G & Group - GD & N \\
\cline { 2 - 5 } & No. & $\%$ & No & 60 \\
\hline I & 14 & 46.66 & 18 & 40 \\
\hline II & 16 & 53.33 & 12 & \\
\hline
\end{tabular}

As shown in [Table-3] In Group-G $46.66 \%$ were ASA-I and and $40 \%$ were ASA-II grade.

53.33 were ASA-II while in Group-GD $60 \%$ were ASA-I

\section{Table 4: Duration of Anaesthesia}

\begin{tabular}{|l|l|l|l|}
\hline & Group - G Mean \pm SD & Group - GD Mean \pm SD & Intergroup 'P' Value \\
\hline Duration(minutes) & $111 \pm 14.52$ & $115.66 \pm 8.97$ & $>0.05$ \\
\hline
\end{tabular}

As shown in [Table-4], Mean duration in Group-G and GD were $111 \& 115.66$ minutes respectively. Group- $G$ and
Group- GD patients were comparable with respect to duration of Anaesthesia.

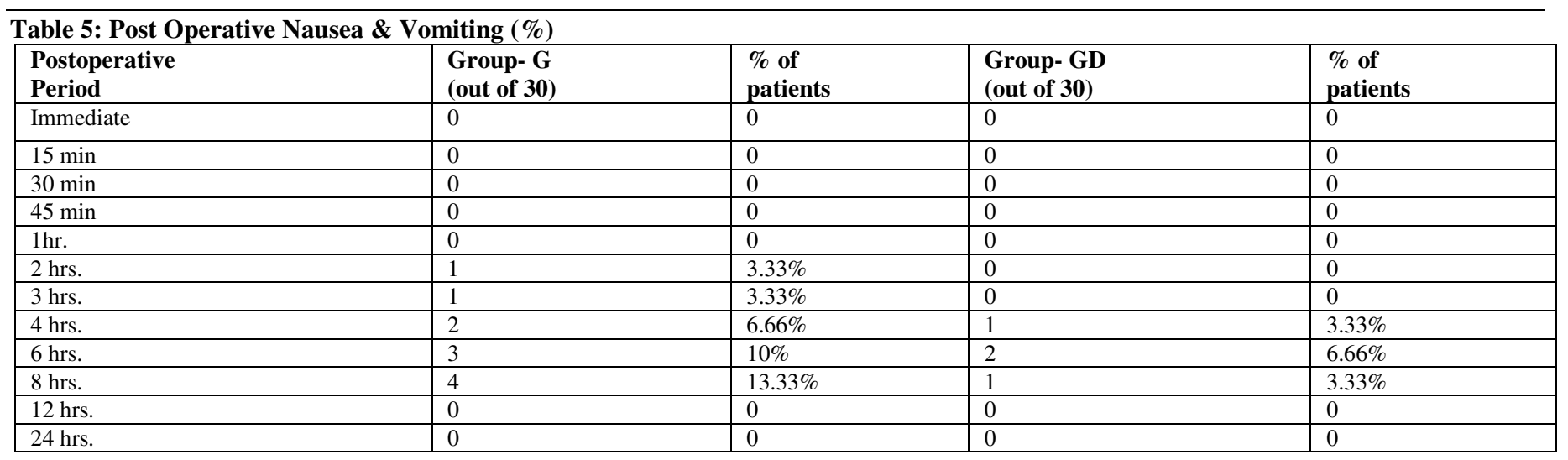

As shown in [Table-5], we observed that complete response (no nausea \& vomiting) was noted up to $4 \mathrm{hrs}$ in Group- GD and only up to $2 \mathrm{hrs}$ in Group-G. The incidence of nausea and vomiting was statistically significantly low in Group-GD at different interval (at $4 \mathrm{hrs}-3.33 \%, 6 \mathrm{hrs}-3.33 \%$ \& $8 \mathrm{hrs}-6.66 \%$ ) as compared to Group-G (at $2 \mathrm{hrs}-3.33 \%, 3 \mathrm{hrs}-3.33 \%$, $4 \mathrm{hrs}-$ $6.66 \%, 6 \mathrm{hrs}-10 \%$ \& 8 hrs- $13.33 \%$ ). 
Table 6: Overall Incidence Of Ponv In 24 Hrs

\begin{tabular}{|l|l|l|l|l|l|}
\hline & Group-G & Group-GD & \% \\
\cline { 2 - 6 } & No. of patients & \% & No. of patients & P Value \\
\hline PONV & 11 & $36.66 \%$ & 4 & $13.33 \%$ & 80.05 \\
\hline $\begin{array}{l}\text { No PONV } \\
\text { (Complete response) }\end{array}$ & 19 & $63.34 \%$ & 26 & $86.67 \%$ & \\
\hline
\end{tabular}

As shown in above table, In Group-GD, only $13.33 \%$ had PONV which was statistically significantly low as compared to Group-G which was $36.66 \%(\mathrm{P}<0.05)$. Complete response in Group-GD was $86.67 \%$ which was statistically significantly high as compared to Group-G which was only $63.34 \%(\mathrm{P}<0.05)$.

\section{Table 7: Emesis Score}

\begin{tabular}{|c|c|c|c|c|c|c|c|c|c|c|}
\hline \multirow{3}{*}{$\begin{array}{l}\text { Post - } \\
\text { operative } \\
\text { Period }\end{array}$} & \multicolumn{6}{|c|}{ Emesis score } & \multicolumn{4}{|c|}{ Rescue Antiemetic } \\
\hline & \multicolumn{2}{|c|}{1} & \multicolumn{2}{|l|}{2} & \multicolumn{2}{|l|}{3} & \multicolumn{2}{|c|}{ No. of patient } & \multicolumn{2}{|l|}{$\%$} \\
\hline & Group G & Group GD & Group G & Group GD & $\begin{array}{l}\text { Group } \\
\text { G }\end{array}$ & Group GD & Group G & Group GD & Group G & Group GD \\
\hline Immediate & 0 & 0 & 0 & 0 & 0 & 0 & 0 & 0 & 0 & 0 \\
\hline $15 \mathrm{~min}$ & 0 & 0 & 0 & 0 & 0 & 0 & 0 & 0 & 0 & 0 \\
\hline $30 \mathrm{~min}$ & 0 & 0 & 0 & 0 & 0 & 0 & 0 & 0 & 0 & 0 \\
\hline $45 \mathrm{~min}$ & 0 & 0 & 0 & 0 & 0 & 0 & 0 & 0 & 0 & 0 \\
\hline $1 \mathrm{hr}$. & 0 & 0 & 0 & 0 & 0 & 0 & 0 & 0 & 0 & 0 \\
\hline $2 \mathrm{hrs}$. & 1 & 0 & 0 & 0 & 0 & 0 & 0 & 0 & 0 & 0 \\
\hline $3 \mathrm{hrs}$. & 0 & 0 & 1 & 0 & 0 & 0 & 1 & 0 & $3.33 \%$ & 0 \\
\hline 4 hrs. & 1 & 1 & 1 & 0 & 0 & 0 & 1 & 0 & $3.33 \%$ & 0 \\
\hline $6 \mathrm{hrs}$. & 1 & 1 & 0 & 1 & 2 & 0 & 2 & 1 & $6.66 \%$ & $3.33 \%$ \\
\hline 8 hrs & 0 & 0 & 2 & 0 & 2 & 1 & 4 & 1 & $13.33 \%$ & $3.33 \%$ \\
\hline $12 \mathrm{hrs}$ & 0 & 0 & 0 & 0 & 0 & 0 & 0 & 0 & 0 & 0 \\
\hline $24 \mathrm{hrs}$ & 0 & 0 & 0 & 0 & 0 & 0 & 0 & 0 & 0 & 0 \\
\hline Total & 03 & 02 & 04 & 01 & 04 & 01 & 08 & 02 & $26.66 \%$ & $6.66 \%$ \\
\hline
\end{tabular}

[Table-7] shows severity of nausea and vomiting by Emesis score in both groups as described above in material and method i.e. Score 0; - No Nausea, Score 1 ;- Nausea only, Score 2 ;- Nausea with Retching, Score 3 ;- Vomiting. Rescue antiemetic was given when emesis socre $\geq 2$ in the form of Inj. Ondensetron $4 \mathrm{mg}$ intravenously.

At $2 \mathrm{hrs}, 1$ patient had score-1 in Group-G \& none in GroupGD.

At 3 hrs, 1 patient had score-2 in Group-G, which required rescue antiemetic.

At $4 \mathrm{hrs}, 1$ patient had score-1in both groups, 1 patient had score-2 in group-G, which required rescue antiemetic was.

At $6 \mathrm{hrs}, 1$ patient had score-1 in both groups, 1 patient had score-2 in group-GD, which required rescue antiemetic \& 2 patients had score-3 in Group-G, which also required rescue antiemetic.

At $8 \mathrm{hrs}, 2$ patients had score- 2 in group-G, 2 patients had score-3 in group-G \& 1patient in Group-GD, so total 4 patients in group-G \& 1 patient in Group-GD required rescue antiemetic.

After12 hrs no incidence of nausea and vomiting was observed.

Requirement of Rescue Anti-Emetic was earlier in Group-G at $3^{\text {rd }} \mathrm{hr}$ as compared to Group-GD which was at $6^{\text {th }} \mathrm{hrs}$. At different interval, Requirement of rescue antiemetic was also lower in Group-GD as compared to Group-G

\begin{tabular}{l}
\hline Table 8: Emesis Score In 24 Hrs \\
\begin{tabular}{|l|l|l|}
\hline EMESIS SCORE & Group-G & Group-GD \\
\hline Score - 0 & 19 & 26 \\
\hline Score -1 & 03 & 02 \\
\hline Score -2 & 04 & 01 \\
\hline Score -3 & 04 & 01 \\
\hline & P 30.05 & \\
\hline
\end{tabular}
\end{tabular}

As shown in above table,

Emesis Score was 0 that is complete response in 26 patients in Group-GD and 19 patients in Group-G.

Emesis Score was 1 in 2 patients in Group-GD and 3 patients in Group-G.

Emesis Score was 2 in 1 patient in Group-GD and 4 patients in Group-G.
Emesis Score was 3 in 1 patient in Group-GD and 4 patients in Group-G.

Emesis score was lower in Group-GD as compared to Group$\mathrm{G}$ which statistically highly significant $(\mathrm{P}<0.05)$. At different interval, Emesis score was also lower in Group-GD as compared to Group-G.

\section{Table 9: Overall Incidence Of Rescue Anti-Emetic In 24 Hrs}

\begin{tabular}{|l|l|l|l|l|}
\hline & Group-G & Group-GD \\
\cline { 2 - 5 } & No. of pt. & $\%$ & No. of pt. & $\%$ \\
\hline Rescue antiemetic & 8 & $26.66 \%$ & 2 & $6.66 \%$ \\
\hline
\end{tabular}


As shown in above table, overall 8 (26.66\%) patients out of 30 required rescue anti-emetic in group-G, while in Group-GD it was only $2(6.66 \%)$ patients out of 30 required anti-emetics, requirements of rescue antiemetic was low in Group-GD as compared to group-G.

\section{Discussion}

As shown in demograghic data, mean age in group-G $42.63 \pm 8.48$ years and in group-GD $43.56 \pm 8.05$ years. Difference between these two group is statistically insignificant $(\mathrm{P}>0.05)$.

B.N. Biswas\& A. Rudra et al (2002); they had taken the patients having mean age in group G-41.3 yrs and group GD42.4yrs. Mohd.Parvez Khan \& Monica Kohali et al (2006) ${ }^{[6]}$ : they had taken the patients having mean age in group $\mathrm{G}$ $38 \pm 9.96$ and group GD $38.84 \pm 9.84$ yrs. Thus our study is in consonance with their study

On comparing weight, mean weight in Group-G was $55.13 \pm 6.47 \mathrm{~kg}$ and in Group-GD $57.13 \pm 7.41 \mathrm{~kg}$. Thus, the weight was comparable between both groups. Difference between the two was statistically not significant $(\mathrm{P}>0.005)$.

B.N. Biswas, \& A. Rudra et al (2002) ${ }^{7}$; they had taken in his study with mean weight in group G $54 \mathrm{kgs}$ and group GD 56kgs. Mohd.Parvez Khan \& Monica Kohali et al (2006) ${ }^{6}$ : they had taken in his study with mean weight in group $\mathrm{G}$ $55.68 \pm 7.12$ and group GD 56.28 \pm 6.63 .

Thus our study is in consonance with their study.

Demographic variable in relation to duration of anaesthesia was $111 \stackrel{1}{\perp}$ 14.52mins in Group-G and $115.66 \pm 8.97$ mins in Group-GD. Difference was statistically insignificant ( $\mathrm{P}>0.005)$.

B.N. Biswas, A. Rudra et al (2002) ${ }^{7}$; duration of anaesthesia in group $G$ was $90 \pm 6 \mathrm{mins}$ and group GD $87 \pm 8$ mins. Mohd.Parvez Khan \& Monica Kohali et al $(2006)^{6}$ : duration of anaesthesia in group G was $105 \pm 8.59$ mins and group GD $107 \pm 12.37$ mins.

Thus our study is in consonance with their study.

The incidence of nausea and vomiting in patients in GroupGD was lower than Group-G at different interval. We observed that no nausea and vomiting (complete response) up to $4 \mathrm{hrs}$ in Group-GD and only up to $2 \mathrm{hrs}$ in Group-G post-operatively. After $12 \mathrm{hrs,}$, we had not found any incidence of nausea and vomiting in both the groups

The cause of nausea and vomiting in early post operatively period can be explained by the effect of residual $\mathrm{CO} 2$ irritating peritoneum, post-operative pain \& effect of inhalation agent used intraoperatively. After $12 \mathrm{hrs}$, there was no incidence of emesis in both groups, which is due to effect of drug and complete removal of residual $\mathrm{CO}_{2} \cdot{ }^{[8,9]}$

The emesis free period was up to 2 hours in Granisetron group and up to 4 hours in Granisetron Dexamethasone combination group which indicates the longer duration of action of combination group.

On comparing the incidence of nausea and vomiting in 24hrs between two groups, the overall incidence of post-operative nausea \& vomiting were $13.33 \%$ in group-GD, which was low, as compared to group-G that was $36.66 \%$ in $24 \mathrm{hrs}$.

We achieved complete response (no nausea $\&$ vomiting, no rescue anti emetic during $24 \mathrm{hr}$ ) in $86.67 \%$ (26) of the patients in group-GD and $63.34 \%$ (19) of the patients in group-G. Thus, complete response was more in group-GD as compared to group-G.
Difference in incidence of PONV between the groups was statistically significant $(\mathrm{P}<0.05)$.

The mechanism of Dexamethasone induced anti emetic activity is not fully understood, but may involve central inhibition of prostaglandin synthesis, decrease in 5HT turnover in central nervous system (i.e. decrease serotonin release) or change in permeability of blood CSF barrier to serum proteins. Granisetron being 5-HT3 receptors antagonist, combining Dexamethasone with it will havesynergistic action on 5-Ht3 receptor. So, the potency of combination group would be higher than single drug in this study.

Our result was similar to B.N. Biswas\& A. Rudra et al (2002), Mohmad. Parvez Kahn \& Monica Kohali et al (2006) and Fujii Y \& Saitosh Y et al (2000).

B.N. Biswas\& A. Rudra et al $(2002)^{[7]}$ observed that the overall incidences $(0-24 \mathrm{hr})$ of PONV were $18.3 \%$ (11) in group-G and5\% (3) in the group-GD $(\mathrm{P}<0.05)$. Completed response (No PONV) were achieved in $83 \%$ of patients in group-G and $95 \%$ of the patients of group-GD. Which showed incidence of PONV in group-GD was significantly low as compared to group-G. Thus, Our result in consonance with this study.

Mohmad Prvez Khan \& Monica Kohali et al (2006) ${ }^{[6]}$ also observed that the incidence of nausea and vomiting was reduced from $75 \%$ in control group to $23.33 \%$ in Grnisetron group and to $5 \%$ in Granisetron Dexamethasone combination group. A complete response (No PONV)occured in $95 \%$ of patients in Granisetron with Dexamethasone group, \& $76.67 \%$ of patients of Granisetron alone $(\mathrm{P}<0.05)$. Thus, Our result in consonance with this study.

Fujji Y et al (2000) ${ }^{[10]}$ observed that completed response (No PONV) was achieved in $83 \%$ of patients in group-G and $98 \%$ of the patients of group-GD. Thus, Our result in consonance with this study.

MohmadPrvez Khan \& Monica Kohali et al (2009) ${ }^{6}$ complete response was observed in $92.5 \%$ in Granisetron Dexamethasone group.

Yamacerhan et al $(2007)^{[11]}$ :observed PONV in $30 \%$ with Granisetron group.

Vishal gupta et al $(2007)^{[12]}$ :observed PONV in $45 \%$ with Granisetron group.

Our study was comparable to Mohd.Parvez Khan \& Monika Kohali et al (2006), Mohd. Parvez Khan \& Monika Kohali et al (2009).

Requirement of Rescue Anti-Emetic was earlier in Group-G at $3^{\text {rd }} \mathrm{hr}$ as compared to Group-GD which was at $6^{\text {th }} \mathrm{hrs}$. At different interval, Requirement of rescue antiemetic was also lower in Group-GD as compared to Group-G $(\mathrm{P}<0.05)$. Rescue anti-emetics given in our study was inj. Ondensetron $4 \mathrm{mg}$ intravenously when emesis $\quad$ scores $\geq 2$, this was taken as end point of study.

Mohd.Parvez Khan \& Monica Kohali et al(2009) they used inj. Ondensetron as rescue antiemetic when emesis score $\geq 2$. Requirement of rescue antiemetic was lower in group-GD as 
compared to group-G.

Thus, our study was comparable with their study. In Group-GD only $6.66 \%$ patients required rescue antiemetic while in Group-G it was $26.66 \%$.So overall requirements of rescue antiemetic was lower in Group-GD as compared to Group-G.

B.N. Biswas\& A. Rudra et al (2002). They observed that $8.33 \%$ (5) of patients in group-G and only $2 \%$ (1) of patients in group-GD required rescue anti emetics during their study. Mohd. Parvez Khan \& Monica Kohali et al (2009): none of the patients required rescue antiemetic in granisetron dexamethasone group. Yamacerhan et al(2007):10\% of patients required rescue antiemetic in granisetron group. Thus, our study was comparable with their study.

\section{Conclusion}

- The overall incidence of post operative nausea and vomiting was significantly less in GranisetronDexamethasone combination group than Granisetron group during 24 hour post operative period.

- The Granisetron-Dexamethasone combination provided longer duration of prophylaxis against post-operative nausea \& vomiting than granisetron alone.

\section{References}

1. Stanaton JM et al. Anaesthesia for laparoscopic cholecystectomy (Letter).Anaesthesia 1991; 46: 317

2. Iitomi $\mathrm{T}$, Toriumi S, Kondo A, Akazawa $\mathrm{T}$, Nakahara $\mathrm{T}$ et al.
Incidence of Nausea and Vomiting after cholecystectomy performed via laparotomy or laparoscopy (Japanese). Masui 1995;44:1627 - 31

3. Watcha Mehernoor F, Paul F. White et al. Postoperative nausea and vomiting: Its etiology, treatment and prevention. Anaesthesiology 1992; 77: 162-184.

4. Kovac Anthony L et al. Prevention and treatment of postoperative nausea and vomiting. Drugs 2000; 59(2): 213-243.

5. Kenny GN et al. Risk factors for postoperative nausea and vomiting. Anesthesia 1994 ;49 (suppl): 6-10.

6. Mohd. Parvez Kahn, Monica Kohali, G.Arunkumar, Vinita Singh et al. Granisetron Dexamethasone combination for prevention of postoperative nausea and vomiting after laparoscopic cholecystectomy; A double blind, placebo controlled study. J Anaesth Clin Pharmacol 2006; 22(3) ; 261-265.

7. Biswas BN, Rudra $\mathrm{A}$ et al. Comparison of granisetron and granisetron plus Dexamethasone for the prevention of postoperative nausea and vomiting after laparoscopic cholecystectomy.ActaAnaesthesiolScand 2003 Jan; 47(1): 79-83.5.

8. Kapur Patricia A. Multicenter study versus nausea outcomes: The value of large numbers and the limitations. AnaesthAnalg 1994; 78: 5-6.

9. WatchaMehernoor $\mathrm{F}$ et al. Postoperative nausea and emesis. AnaesthesiolClin North America. 2002; 20 (3): 471-84.

10. Fujii Y, Saitoh Y, Toyooka $\mathrm{H}$ et al. Granisetron/Dexamethasone combination for the prevention of postoperative nausea and vomiting after laparoscopic cholecystectomy.Eur J Anaesthesiol. 2000 Jan; 17 (1);64-8.

11. YamacErhan, Elvan Erhan, HasanAydede, OkanYumus and Alp Yentur et al. Ondansentron, granisetron and dexamethasone compared for the prevention of postoperative nausea and vomiting in patients undergoing laproscopic cholecystectomy. A randomized lacebo-controlled study.SurgEndosc. 2008 Jun; 22(6): 1487 - 92.

12. Wang JJ, Ho ST, Lee Sc, Liu et al. The use of Dexamethasone for preventing PONV in females undergoing thyroidectomy: A comparison of Droperidol with saline. AnaesthAnalg 1999; 89: 2003.

Copyright: () the author(s), publisher. Academia Anesthesiologica Internationalis an Official Publication of "Society for Health Care \& Research Development". It is an open-access article distributed under the terms of the Creative Commons Attribution Non-Commercial License, which permits unrestricted non-commercial use, distribution, and reproduction in any medium, provided the original work is properly cited.

How to cite this article: Rani BN, Bhatt S. A study to compare and evaluate the efficacy of Granisetron and Granisetron Dexamethasone combination as Anti-emetic. Acad. Anesthesiol. Int. 2019;4(2):78-83.

DOI: dx.doi.org/10.21276/aan.2019.4.2.22

Source of Support: Nil, Conflict of Interest: None declared. 